\title{
Reciprocal transplants support a plasticity-first scenario during colonisation of a large hyposaline basin by a marine macro alga
}

\author{
Daniel Johansson ${ }^{1,2}$, Ricardo T. Pereyra ${ }^{1,2}$, Marina Rafajlović ${ }^{2,3}$ and Kerstin Johannesson ${ }^{1,2^{*}}$ (1)
}

\begin{abstract}
Background: Establishing populations in ecologically marginal habitats may require substantial phenotypic changes that come about through phenotypic plasticity, local adaptation, or both. West-Eberhard's "plasticity-first" model suggests that plasticity allows for rapid colonisation of a new environment, followed by directional selection that develops local adaptation. Two predictions from this model are that (i) individuals of the original population have high enough plasticity to survive and reproduce in the marginal environment, and (ii) individuals of the marginal population show evidence of local adaptation. Individuals of the macroalga Fucus vesiculosus from the North Sea colonised the hyposaline $(\geq 2-3 \%$ ) Baltic Sea less than 8000 years ago. The colonisation involved a switch from fully sexual to facultative asexual recruitment with release of adventitious branches that grow rhizoids and attach to the substratum. To test the predictions from the plasticity-first model we reciprocally transplanted F. vesiculosus from the original population (ambient salinity 24\%o) and from the marginal population inside the Baltic Sea (ambient salinity 4\%o). We also transplanted individuals of the Baltic endemic sister species F. radicans from 4 to $24 \%$. We assessed the degree of plasticity and local adaptation in growth and reproductive traits after 6 months by comparing the performance of individuals in 4 and 24\%.

Results: Branches of all individuals survived the 6 months period in both salinities, but grew better in their native salinity. Baltic Sea individuals more frequently developed asexual traits while North Sea individuals initiated formation of receptacles for sexual reproduction.

Conclusions: Marine individuals of F. vesiculosus are highly plastic with respect to salinity and North Sea populations can survive the extreme hyposaline conditions of the Baltic Sea without selective mortality. Plasticity alone would thus allow for an initial establishment of this species inside the postglacial Baltic Sea at salinities where reproduction remains functional. Since establishment, the Baltic Sea populations have evolved adaptations to extreme hyposaline waters and have in addition evolved asexual recruitment that, however, tends to impede local adaptation. Overall, our results support the "plasticity-first" model for the initial colonisation of the Baltic Sea by Fucus vesiculosus.
\end{abstract}

Keywords: Common garden, Reciprocal transplant, Salinity, Asexual reproduction, Fucus vecisulosus, Fucus radicans, Baltic Sea

\section{Background}

Some species are able to establish populations in ecologically marginal habitats where the physical environment is radically different from the species' native environment.

\footnotetext{
*Correspondence: Kerstin.Johannesson@marine.gu.se

1 Department of Marine Sciences, University of Gothenburg, Tjärnö, Strömstad, Sweden

Full list of author information is available at the end of the article
}

If a marginal habitat is relatively local, a population may be established and sustained by continuous recruitment of individuals from a nearby population forming a "source-sink" relationship [1]. However, some marginal environments are larger than the typical dispersal distance of a species, and populations established in these areas must be self-sustained. If this requires new phenotypic traits or phenotypic buffering [2], plasticity and/or 
directional selection need to be involved in the tuning of traits so that the individuals survive the new environment. Plasticity may seem to be the ideal mechanism, as colonisation in the presence of plasticity can take place without significant losses of genetic variation [3]. However, various constraints including increased costs of plasticity may put a halt to colonising new environments [4]. Moreover, plasticity may not always be adaptive and establishing a population in an environment outside the range of the native environmental variation may increase the risk of plasticity being harmful. If genetic variation is already present in a population as standing genetic variation, local adaptation by means of directional selection may be an efficient and rapid alternative to plasticity [5]. In comparison to plasticity, however, selection will, most likely, be accompanied by much larger loss of genetic variation. If new mutations are required, adaptation will be limited by the waiting time for these, which is usually very long [6]. Furthermore, local adaptation may be counteracted by gene flow [1], and restricted by demographic characteristics of species, such as small population sizes and long generation times [7]. On the other hand, it has been shown that hybridisation and introgression may contribute new genetic variation that may support local adaptation [8].

The Baltic Sea is one of the world's largest brackishwater environments, and, as such, a truly marginal marine habitat. This postglacial semi-enclosed brackish water basin formed from a freshwater lake that opened to the sea about 8500 years ago [9]. Today the Baltic Sea has a surface salinity ranging from 2 to $3 \%$ in its innermost parts, $6-8 \%$ in the central parts, and towards the opening to the North Sea, through the Danish Straits, salinity changes rapidly from $\sim 8$ to $\sim 20 \%$. Outside these straits, surface salinity successively increases to full marine salinity $(>30 \%)$ in the western part of the North Sea.

Since the opening, the Baltic Sea has been colonised by marine species, some of which have been introduced from other parts of the world [10], but the bulk of marine species have invaded the Baltic Sea from nearby areas of the North Sea. Following the North Sea-Baltic Sea transect, a majority of the marine species shows genetic clines that are steepest in the Danish Straits where the salinity gradient is strongest [11]. The steep clines are caused by local adaptation (e.g. [12, 13]), and isolation effects related to this.

Fucoid macroalgae are foundation species of rockyshore ecosystems in temperate and subarctic waters. Of a handful of Atlantic species, one species, Fucus vesiculosus, has been able to establish populations deep inside the Baltic Sea including areas of strong hyposaline $(2-4 \%$ ) waters, such as the inner parts of the Gulf of Riga, the Gulf of Finland and the Bothnian Sea [14,
15]. A most intriguing finding is that the colonisation of the Baltic Sea is paralleled by a switch from what seems to be obligate sexual recruitment of new attached thalli outside the basin, to facultative asexual recruitment of new attached and fully sexually reproduced thalli inside the basin [16]. It has been suggested that this switch is due to an increased risk of polyspermy and failure of sexual reproduction in hyposaline waters [17]. However, predominance of recruitment by cloning is not everywhere correlated to salinity [18]. During establishment of $F$. vesiculosus in the Baltic Sea, a separate species ( $F$. radicans) diverged from the Baltic lineage of $F$. vesiculosus $[19,20]$. Fucus radicans is endemic in the Baltic Sea. It is sympatric with $F$. vesiculosus over large parts of the Bothnian Sea and in Estonia [15, 21]. Both species are dioecious with both males and females being capable of asexual reproduction.

Asexual reproduction in Baltic Sea populations of both species is accomplished by the production of adventitious branches that come loose and reattach to the bottom by formation of rhizoids [16]. Adventitious branches are present also in thalli of Fucus outside the Baltic Sea, where they have most likely been formed after physical damage from grazers [22], but asexual formation of new thalli has never been reported outside the Baltic Sea.

We hypothesised that the establishment in the Baltic Sea by $F$. vesiculosus may have followed the plasticity-first model [3]. We investigated this by testing two predictions from the model: (i) individuals of the original population have high enough plasticity to tolerate the marginal environment, and (ii) individuals of the marginal population show evidence of local adaptation. The Baltic Sea populations of $F$. vesiculosus and $F$. radicans both descend from a common $F$. vesiculosus lineage originating in the eastern part of the North Sea, close to the entrance of the Baltic Sea [21]. Thus we used individuals from a population in this area to represent the ancestors from which the current Baltic Sea individuals of both species have derived. We used a reciprocal transplant experiment [23] to compare the development of key traits between North Sea and Baltic Sea populations in both native and non-native salinity. This allowed us to separate between locally adapted and plastic traits. To avoid confounding effects from the native environment we used small adventitious branches that were detached from the mother thalli and cultured during 6 months in the laboratory. We assessed survival and measured growth rate as proxies for physiological tolerance and general fitness. We also recorded formation of a second generation of small adventitious branches from the first generation branches and the formation of rhizoids from the primary branches. Both formation of adventitious branches and formation of rhizoids are necessary to accomplish 
asexual reproduction. Finally, we recorded formation of receptacles as a proxy for the allocation of resources into sexual reproduction.

\section{Methods}

\section{Sampling and characterisation}

We sampled $F$. radicans and $F$. vesiculosus (73 individuals in total) from a sympatric site on the Swedish coast of the

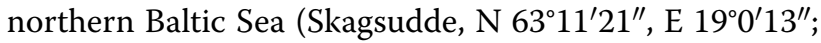
Fig. 1). In addition, we sampled 20 individuals of $F$. vesiculosus from a North Sea population on the Swedish west

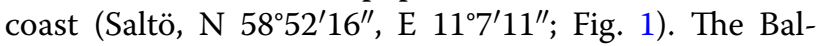
tic samples were from a depth of 3-6 $\mathrm{m}$ and an average salinity of $4 \%$, while the North Sea samples were from the intertidal, with fluctuating salinity around an average of $24 \%$ (range $15-30 \%$ ). Sampling was performed in July 2011 and fresh thalli were brought to the laboratory and stored in tanks with water of ambient salinity (4 and $24 \%$, respectively). We hereafter refer to each of these three samples (F. radicans from the Baltic Sea, F. vesiculosus from the Baltic Sea, and F. vesiculosus from the North Sea) as our three "populations". Formal identification of the individuals within each sample was done by D.J. on basis of morphological criteria and microsatellite genotype.

For the two Baltic Sea species we performed a first separation based on morphology and confirmed (or in a few cases, corrected) the identification using genotypes in 9

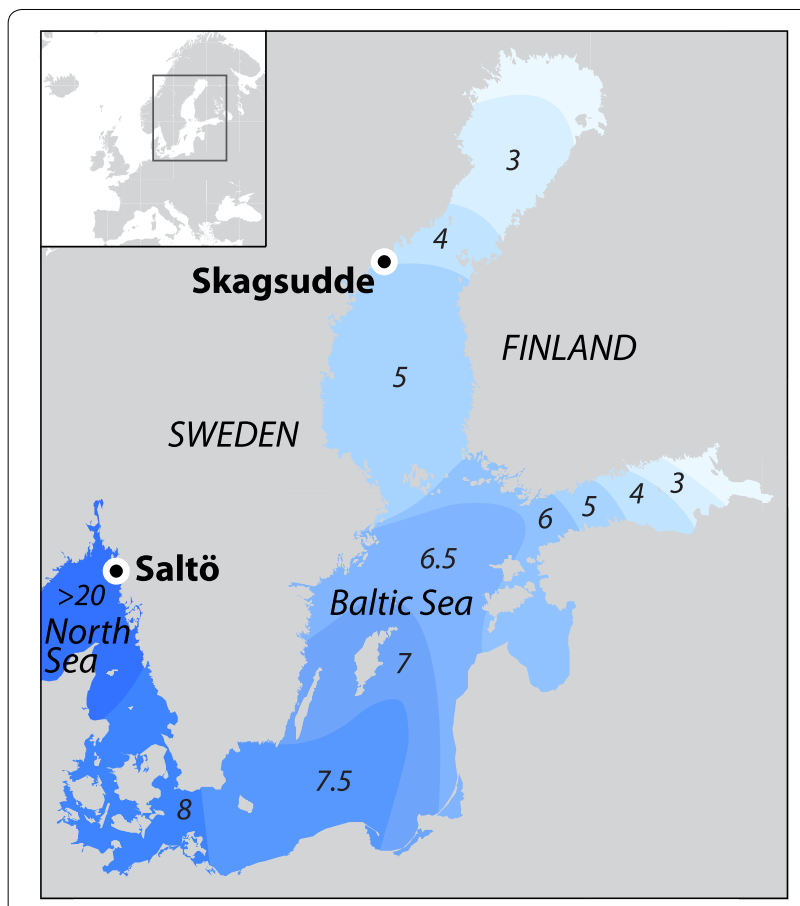

Fig. 1 Map showing sampling sites and the Baltic Sea salinity gradient. Source: Online Map Creation-Martin Weinelt, http://aquarius. ifm-geomar.de, visited 2009.05.01 microsatellite markers. Extraction of DNA, PCR reactions and microsatellite analyses were done following the description in [24]. The software STRUCTURE [25] was used to assign individuals into genetically coherent groups, and GENCLONE [26] was used to identify clones among the Baltic Sea individuals. All individuals from the North Sea, on the other hand, were a priori assumed to be unique multi-locus genotypes as asexual reproduction has never been reported from outside the Baltic Sea [16, 27].

We assessed background phenotypic differentiation between Atlantic and Baltic Sea populations by measuring variation in morphological traits in all thalli sampled in the field using the traits earlier described to discriminate between the two species [19]. The measurements included distance between the two most distant dichotomies on a branch, frond width measured midway between the same two dichotomies (both these measurements were repeated in five branches per individual), stipe length measured as the distance between the holdfast and the first branching point, and total length measured as the distance between the holdfast and the most distal tip. We used principal components analysis to assess overall differences among the three populations in size and shape.

In a long-term (6 months) reciprocal transplant experiment North Sea and Baltic Sea adventitious branches detached from large thalli grew new vegetative tissue in both 4 and $24 \%$ salinity. In this experiment each individual was represented by six $\approx 1 \mathrm{~cm}$ long adventitious branches that we randomly chose from a large number of adventitious branches grown on each individual. We used 48 individuals of Baltic $F$. radicans, 25 of Baltic $F$. vesiculosus and 20 of North Sea F. vesiculosus. Three branches from each individual were acclimatised to the low salinity and three to the high, by adjusting the salinity gradually over 4 weeks for those transplanted to a non-native salinity. The adventitious branches were incubated upright, attached with elastic threads to holders in tanks with $40 \mathrm{~L}$ water and flow-pumps to circulate the water. We used two tanks per salinity and individuals were randomly distributed between these while keeping numbers of individuals from each population constant in each tank. The water was prepared by mixing tap water with "Instant Ocean" salt and nutrient medium. Water was changed once every 2nd month. The experiment was run in a thermo constant room at $13^{\circ} \mathrm{C}$ and a $16: 8 \mathrm{~h}$ light: dark cycle for 6 months. The length increment of each adventitious branch was measured at the end of the experiment. In addition, we counted the number of new adventitious branches ("secondary branches") formed from the starting branches. Rhizoids (used to attach the vegetative part to the substratum) were formed at the 
basal end of some of the primary adventitious branches, and we noted presence or absence of rhizoids in any of the three replicate branches of the same individual after inspection using a stereomicroscope. Some of the primary adventitious branches also formed early stages of receptacles and in a similar way, we recorded presence or absence of these in each individual.

\section{Statistical analysis}

We conducted two separate analyses for each response parameter. In one analysis we compared the two sympatric populations of $F$. radicans and $F$. vesiculosus from the Baltic Sea. In a separate analysis we compared the Baltic and North Sea populations of $F$. vesiculosus. For all tests including $F$. radicans we performed analyses with both the full dataset, and datasets that were made balanced $(N=20)$ by random removal of individuals, using typeIII sums of squares in the unbalanced cases. As results obtained in balanced and full data sets remained qualitatively the same, we only present the result of the balanced data set in figures and tables.

As adventitious branches of each individual were grown in both salinities (see above), we used a split-plot design for the analysis of variance (ANOVA). We assessed assumptions of normality and homogeneity of variances with box-plots and residual plots. Log transformation improved the growth data, which was analysed using the aov function in R (v. 2.15.2; [28]). Data on formation of secondary adventitious branches were analysed as a split-plot design with linear mixed-effects models using the lme function. We analysed occurrence (presence/ absence) of rhizoids using Fisher's exact test, comparing species and origin separately. As rhizoids only formed in the high salinity in all three populations, the low salinity data was not included in the analysis. Receptacles were only formed by one population and in one salinity treatment, and these results were left without statistical evaluation. Confidence intervals for all means were calculated by multiplying standard error with the critical $t$-value at a confidence level of $95 \%$.

\section{Results}

In the Baltic Sea site where both F. radicans and F. vesiculosus were sampled, the preliminary assignment of individuals to species, based on overall morphology, was mostly consistent with the result of the genetic analysis. Among the individuals sampled, however, four individuals were not correctly assigned from morphology and were moved to the correct taxa for all down-stream analyses after genotyping (Additional file 1). The genotyping further showed that the Baltic population of $F$. vesiculosus consisted of 10 unique multi-locus genotypes and 7 clones with 2-3 individuals per clone (in total 17 genotypes), while the population of $F$. radicans included 2 unique individuals and three clones with 9, 17 and 20 individuals each (in total 5 genotypes). Despite the replication of genotypes, in particular in $F$ radicans, we decided to include all individuals sampled in the experiment, in order to form a representative sample of a wild population from the Baltic Sea and to detect (if present) contributions from somatic mutations. Separate analyses were in addition done comparing traits among the three major clones of the $F$. radicans samples (see below).

The morphology of the adult thalli sampled in the wild revealed phenotypic variation among the three populations along the $\mathrm{PC} 1$ axis, reflecting population differences in overall size. Individuals of Fucus vesiculosus from the North Sea were, on average, larger than individuals of Baltic Sea $F$. vesiculosus, and individuals of $F$. radicans were the smallest (Fig. 2). There was no separation of the populations along the PC2 axis and this suggests that there were no major differences in shape among the three populations. The within population variation along the PC2 axis tended to be highest in the North Sea $F$. vesiculosus and lowest in the $F$. radicans population.

Among the adventitious branches transferred to a nonnative salinity (from 4 to $24 \%$, or the reverse), 1-3 (and usually 3 ) of the replicate branches of each individual survived and formed new tissue during the 6 months experiment, indicating high plasticity in the physiological response to environmental salinity. However, comparing growth of Baltic and North Sea F. vesiculosus, we found a strong interaction between salinity and origin

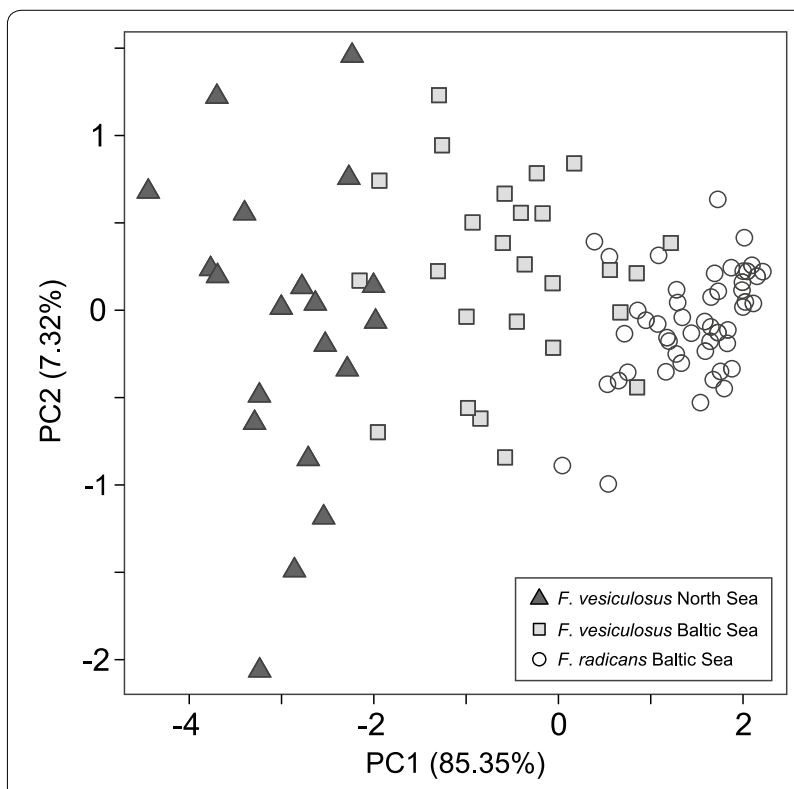

Fig. 2 Principal components analysis of four morphological characters (see text) in adult populations of F. vesiculosus from Saltö (North Sea), F. vesiculosus from Skagsudde (Baltic Sea) and F. radicans from Skagsudde (Baltic Sea) 
$(P<0.001$; Table 1$)$, indicating that both populations of $F$. vesiculosus grew better in their native salinity than in the other salinity. This supports that Baltic Sea populations have evolved local adaptation in traits that contribute to growth (Fig. 3a). Also the Baltic Sea population of F. radicans grew better in the hyposaline conditions of its native environment than in fully marine waters (Fig. 3a). Notably, $F$. radicans was less negatively impacted by high

Table 1 ANOVA (split-plot design) analysing growth of adventitious branches during 6 months in a reciprocal transplant experiments as an effect of salinity (4 and $24 \%$ ) , species and origin

\begin{tabular}{lccccc}
\hline Source & $\mathbf{d} \boldsymbol{S}$ & SS & MS & $\boldsymbol{F}$ & $\boldsymbol{P}$ \\
\hline A. Baltic Sea F. radicans vs. F. vesiculosus & & & & \\
Species & 1 & 0.688 & 0.688 & 2.191 & 0.148 \\
Residuals & 36 & 11.312 & 0.314 & & \\
Salinity & 1 & 4.782 & 4.782 & 35.67 & $<0.001$ \\
Species*salinity & 1 & 0.662 & 0.662 & 4.939 & 0.033 \\
Residuals & 36 & 4.826 & 0.134 & & \\
B. Baltic Sea F. vesiculosus vs. North Sea F. vesiculosus & & \\
Origin & 1 & $<0.001$ & $<0.001$ & $<0.001$ & 0.985 \\
Residuals & 36 & 10.62 & 0.295 & & \\
Salinity & 1 & 0.052 & 0.052 & 0.375 & 0.544 \\
Origin*salinity & 1 & 7.689 & 7.689 & 55.757 & $<0.001$ \\
Residuals & 36 & 4.964 & 0.138 & & \\
\hline A. Comparison of growth rates & between F.radicans and F.vesiculosus from
\end{tabular}

A. Comparison of growth rates between F. radicans and F. vesiculosus from a sympatric site in the Baltic Sea. B. Comparison of growth rates between $F$. vesiculosus from North Sea and Baltic Sea. See also Fig. 3a salinity than was Baltic $F$. vesiculosus, resulting in a significant interaction be-tween salinity and species also in this comparison $(P=0.033$; Table 1 ; Fig. 3a). We also compared growth rates among the three numerically dominant clones of $F$ radicans from the Baltic Sea and found a statistically significant effect of clone on growth with a similar trend of higher growth in the low salinity in all clones (Table 2; Fig. 4a), supporting the presence of genetic variation in this trait.

Secondary adventitious branches were formed from the basal part of the original adventitious branches in all three populations during the experimental period. When we compared the two populations of $F$. vesiculosus from the North Sea and the Baltic Sea, respectively, we found no significant effect of salinity and no interaction between salinity and origin, but a trend towards higher numbers of secondary adventitious branches in the Baltic population than in the North Sea population $(P=0.073$; Table 3; Fig. 3b). Comparing the two sympatric populations from the Baltic Sea, F. radicans and Baltic F. vesiculosus, we found no significant interaction of species and salinity, and no significant effect of salinity alone. However, there was a strong difference between the two species $(P<0.001$, Table 3$)$, that is, Fucus radicans formed significantly more secondary adventitious branches than did sympatric individuals of $F$. vesiculosus in both salinities (Fig. 3b). Also in this trait we found differences among clones with one clone growing more adventitious branches than the other two clones, showing genetic variation being present in this trait (Table 4; Fig. 4b).
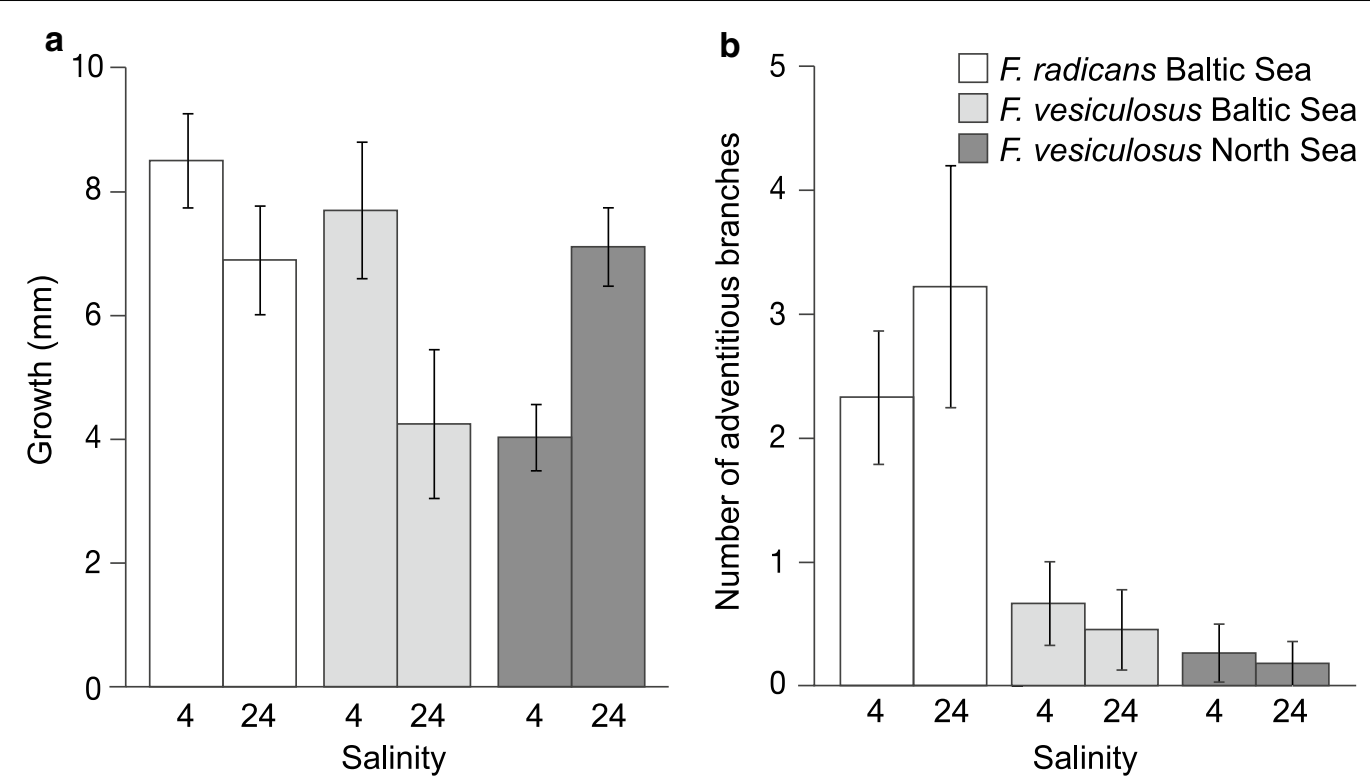

Fig. 3 Result of reciprocal transplants of North Sea and Baltic Sea Fucus during 6 months in 4 and 24\%o salinity. a Growth of 10 mm large adventitious branches. $\mathbf{b}$ Number of secondary branches formed per primary branch. Error bars show $95 \% \mathrm{Cl}$ 
Table 2 ANOVA (split-plot design) analysing growth of adventitious branches during 6 months in a reciprocal transplant experiments as an effect of salinity (4 and 24\%o), among three clones of Fucus radicans from Skagsudde (Baltic Sea), see also Fig. 4a

\begin{tabular}{lrrrrl}
\hline Source & $\boldsymbol{d f}$ & \multicolumn{1}{c}{$\boldsymbol{S}$} & $\boldsymbol{M S}$ & $\boldsymbol{F}$ & $\boldsymbol{P}$ \\
\hline Clone & 2 & 167.9 & 83.97 & 7.57 & 0.002 \\
Residuals & 43 & 476.9 & 11.09 & & \\
Salinity & 1 & 54.7 & 54.72 & 16.45 & $<0.001$ \\
Clone* Salinity & 2 & 5.22 & 2.61 & 0.784 & 0.46 \\
Residuals & 43 & 143.1 & 3.33 & & \\
\hline
\end{tabular}

Some of the primary adventitious branches developed rhizoids and attached to the substratum, but unexpectedly rhizoids were only formed in the higher salinity treatment $(24 \%)$. The proportion of individuals that developed rhizoids was different among the three populations with $61 \%$ of $F$. radicans individuals and $20 \%$ of Baltic Sea $F$. vesiculosus forming rhizoids, but none of the North Sea $F$. vesiculosus did form rhizoids. In the sympatric Baltic Sea site, the difference between the two species was significant, and the difference between $F$. vesiculosus of Baltic Sea and North Sea origin was in addition marginally significant (Table 5). There was, however, no significant difference in how many individuals formed rhizoids among the three clones of $F$. radicans (results not shown). Although not quantified, we observed that most of the adventitious branches that formed rhizoids also attached to the substratum.
In $35 \%$ of the North Sea individuals the adventitious branches formed early stages of receptacles in the high salinity treatment. No receptacles were developed in the adventitious branches from the two Baltic populations in high or low salinity, or in adventitious branches of the North Sea population kept in low salinity.

\section{Discussion}

West-Eberhard [3] suggests that developmental plasticity is likely to precede the accumulation of genetic divergence during colonisation of a new environment. The mechanism is simply that a population in which all individuals survive the new environment by being plastic will avoid demographic bottlenecks during establishment caused by selective mortality. Following successful colonisation, assimilation of genetic differences that improves phenotypes and result in local adaptation of traits may follow [3]. Here we raise the question if the colonisation of the Baltic Sea by $F$. vesiculosus was initially made possible by a high degree of plasticity, but later followed by assimilation of genetic differences caused by directional selection that improved local adaptation and allowed for further colonisation up to the current range margin in extreme hyposaline waters. The plasticity-first model is supported if colonising individuals without prior adaptation will survive and reproduce in the new environment due to their plasticity. In contrast to a model where colonisation would only be possible under selective mortality, establishment aided by plasticity would give less serious demographic effects and probably less loss of genetic
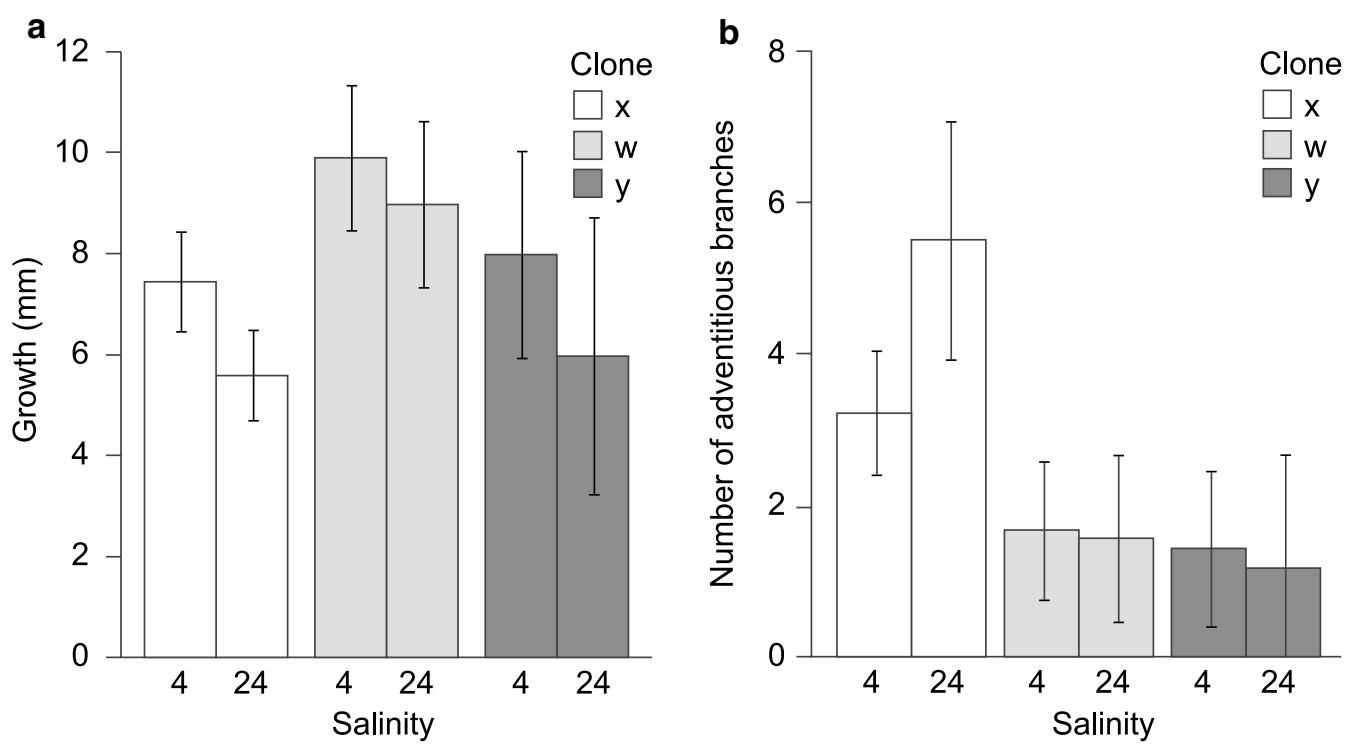

Fig. 4 The same experiment as in Fig. 3, comparing the results for the three large clones of Fucus radicans. $N=20$ for clone X, 17 for W and 9 for $Y$. a Growth of $10 \mathrm{~mm}$ large adventitious branches. b Number of secondary branches formed per primary branch. Error bars show $95 \% \mathrm{Cl}$. (For statistic evaluation see Tables 2 and 4 .) 
Table 3 ANOVA (linear mixed effects model, $d f=1.34$ ) analysing the number of secondary formed adventitious branches per primary branch, during 6 months in a reciprocal transplant experiments, as an effect of salinity (4 and $24 \% o$ ), species and origin

\begin{tabular}{lcl}
\hline Source & $\boldsymbol{F}$ & $\boldsymbol{P}$ \\
\hline A. Baltic Sea F. radicans vs. F. vesiculosus & & \\
Intercept & 36.45 & $<0.001$ \\
Salinity & 0.876 & 0.36 \\
Species & 15.65 & $<0.001$ \\
Salinity*species & 2.648 & 0.11 \\
B. Baltic Sea F. vesiculosus vs. North Sea F. vesiculosus & & \\
Intercept & 24.74 & $<0.001$ \\
Salinity & 1.989 & 0.17 \\
Origin & 3.42 & 0.07 \\
Salinity*origin & 0.261 & 0.61 \\
\hline
\end{tabular}

A. Analysing the effect of salinity and species (F. radicans and $F$. vesiculosus) from the same origin in the Baltic Sea. B. Analysing the effect of salinity and origin (North Sea and Baltic Sea) in populations of F. vesiculosus. See also Fig. 3b

Table 4 Linear mixed-effects model of number of secondary adventitious branches formed by the three clones of Fucus radicans from Skagsudde during growth in a common garden at two different salinities (see also Fig. 4b)

\begin{tabular}{lccc}
\hline & df & $\boldsymbol{F}$ & $\boldsymbol{P}$ \\
\hline Intercept & 1.43 & 136.8 & $<0.001$ \\
Salinity & 1.43 & 0.049 & 0.83 \\
Clone & 2.43 & 15.63 & $<0.001$ \\
Clone*salinity & 2.43 & 3.24 & 0.049 \\
\hline
\end{tabular}

Table 5 Proportion of individuals forming rhizoids in the three study populations of Fucus

\begin{tabular}{|c|c|c|}
\hline \multicolumn{2}{|l|}{ Baltic Sea } & \multirow{2}{*}{$\begin{array}{l}\text { North Sea } \\
\text { F. vesiculosus }\end{array}$} \\
\hline Fucus radicans & F. vesiculosus & \\
\hline $61 \%$ & $20 \%$ & $0 \%$ \\
\hline \multicolumn{3}{|l|}{$P=0.003$} \\
\hline & $P=0.053$ & \\
\hline
\end{tabular}

$P$ values are derived from Fisher's exact test

variation by selection and drift, although plasticity would mask the genetic variation present in traits and may prevent improvements in fitness by local adaptation.

We here show that contemporary individuals of the North Sea population of $F$. vesiculosus have a high tolerance to low salinity and survive and grow in strongly hyposaline $(4 \%$ ) waters. Assuming a similar capacity in the North Sea population during the time of the Baltic Sea invasion of $F$. vesiculosus, the individuals that colonised the Baltic Sea were capable of surviving at salinities currently found at the range margin of the Baltic Fucus distribution. However, for successful establishment in the Baltic Sea without prior local adaptation, also traits central to reproduction must remain functional in the low salinity. Indeed, an earlier study of sexual reproduction shows that gametes of $F$. vesiculosus from the North Sea remain functional down to salinities around $7-8 \%$ o [17]. Thus high levels of plasticity in survival, growth and sexual function suggest that populations from the North Sea were able to rapidly colonise the southern part of the hyposaline Baltic Sea after its postglacial formation, or even more central parts as salinity during a period around 6000 years ago was higher than today [9]. Due to the lack of selective mortality this phase of the colonisation was presumably relatively rapid, and without major losses of genetic variation. Following the establishment in the southern and central parts of the Baltic Sea, the population seems to have improved its fitness by directional selection. The selection led to local adaptation and higher growth rate in $4 \%$ compared to $24 \%$ salinity, as shown in this study (and see [29]). Also local adaptation in sexual reproduction has taken place as current Baltic Sea populations maintain high sperm quality and rate of fertilisation below $8 \%$ [17]. There is also support for local adaptation in other traits of Baltic Sea F. vesiculosus and $F$ radicans. For example, tolerance to emersion stress is lost in Baltic Sea populations following the switch to a more subtidal distribution [30], and a majority of genotypes in $F$. radicans have reduced tolerance to stress from desiccation and freezing [31]. Thus following the initial phase of establishment in the Baltic Sea supported by plasticity, the second phase involving selection towards increased fitness in hyposaline waters seems also to have extended the distribution of the $F$. vesiculosus lineage (including the $F$. radicans branch) to its current range margins in extremely low salinities (3-4\%).

As part of the second phase of local adaptation, the new role of the adventitious branches is intriguing. The original (North Sea) role of these vegetative parts was probably to repair tissue damaged by grazers [22]. In the northern Baltic Sea, by contrast, adventitious branches form, fall off and develop rhizoids that reattach them to the substratum, and from there they grow clonal copies of the mother thallus. Formation of adventitious branches was most frequent in $F$. radicans, less frequent in the Baltic Sea F. vesiculosus, and least common or absent in North Sea $F$. vesiculosus in our experiments, which correlates to the prevalence of clones in these populations (this study and [32]). Asexual reproduction by means of re-attaching adventitious branches seems to be a unique trait to the Baltic Sea that in itself has promoted the spread and establishment in a new area. The 
reason for this may be that after its initial occurrence, asexual reproduction may have spread in the northern Baltic Sea by directional selection favouring individuals that invested more in asexual than in sexual reproduction. The observation of polyspermy in salinities below 5-6\% [33] supports a selection-driven switch to asexual reproduction in hyposaline waters. Polyspermy may severely constrain sexual reproduction, at least in populations where gamete densities are high. Under risk of polyspermy, individuals that allocate more energy to formation of adventitious branches and less to building receptacles and forming gametes would be favoured by selection.

However, in the field also thalli recruited asexually form receptacles and produce gametes that are functional $[16$, 34]. This suggests that selection for asexual reproduction in hyposaline areas is not particularly strong. In addition, the observation that the prevalence of asexual recruitment is very variable and not correlated to salinity [18] suggests directional selection imposed by salinity being a less likely explanation for the spread of asexual recruitment inside the Baltic Sea. Alternatively, the distribution of clones may be a consequence of neutral processes during colonisation of the Baltic Sea (that is, random dispersal and demographic stochasticity). Indeed, according to recent modelling results, it seems highly likely that if asexual reproduction is an option, then fully neutral processes are likely to drive structuring of the population and determine the distribution of asexual populations during a colonisation event without involvement of selection on individual reproductive fitness [35].

\section{Conclusions}

Fucus vesiculosus is the only Atlantic lineage of fucoid algae that has been able to colonise deep into the Baltic Sea including environments with strong hyposaline conditions. As shown in this study, North Sea individuals of this species are tolerant enough to survive at least several months in salinities corresponding to the hyposaline conditions at the range margin of Baltic Sea populations. Moreover, as shown in an earlier study [17], sexual reproduction in North Sea F. vesiculosus is sustained down to salinities typical of the central Baltic Sea. Thus, plasticity in growth and sexual reproduction seemed strong enough to allow for an initial colonisation phase into the central Baltic Sea without selective mortality, corroborating the primary prediction of the plasticity-first model of West-Eberhard [3]. Furthermore, growth of North Sea individuals is already plastic enough to sustain survival down to strongly hyposaline waters at the current Baltic Sea range margins, and this trait was thus "preadapted" to colonise deeper into the Baltic Sea upon arrival of the first populations. Sexual reproduction, on the other hand, was only enough plastic to sustain recruitment into the central Baltic Sea, but a dramatic switch to asexual reproduction most likely boosted further colonisation of more marginal areas. Both strong plasticity and dominance of asexual recruitment somewhat impede the action of selection. But, nevertheless, the Baltic Sea Fucus shows evidence of local adaption in several key traits supporting the second prediction of the plasticity-first hypothesis that the initial phase of colonisation is followed by improved fitness and local adaptation through directional selection [3].

\section{Additional file}

Additional file 1. Result of structure analysis. This analysis was used to confirm species assignment in the sympatric sample of Fucus radicans and F. vesiculosus from the Baltic Sea site.

\section{Authors' contributions}

DJ, RTP and KJ planned the study and sampled the material. DJ genotyped the material with the help of RTP, run the experiments and performed the statistical analyses. KJ and DJ wrote the manuscript with the help of MR. All authors read and approved the final manuscript.

\section{Author details}

${ }^{1}$ Department of Marine Sciences, University of Gothenburg, Tjärnö, Strömstad, Sweden. ${ }^{2}$ Centre for Marine Evolutionary Biology, University of Gothenburg, Tjärnö, Strömstad, Sweden. ${ }^{3}$ Department of Physics, University of Gothenburg, Gothenburg, Sweden.

\section{Acknowledgements}

We are grateful to Gerry Quinn and Jon Havenhand for advice on statistical analyses, and to Angelica Ardehed, Ellen Schagerström and Lena Kautsky for advices and practical support during field campaigns.

\section{Competing interests}

The authors declare that they have no competing interests.

\section{Availability of data and materials}

The datasets used and analysed during the current study is available from the corresponding author on reasonable request.

\section{Ethics approval and consent to participate}

The sampling of this species did not require permission from any local or national authority as sampled only in areas with full access to anyone to pick seaweeds. The sampled species are not classified as endangered, and are not under any protection in the sampled area.

\section{Funding}

Funding was provided by the BONUS project (Baltic Organisations Network for funding Science EEIG) to the BaltGene and Bambi projects, and by the Swedish Research Council VR, through a Linnaeus grant to the Centre for Marine Evolutionary Biology (CeMEB). The funding bodies had no role in the design of the study and collection, analysis, and interpretation of data, or in writing the manuscript.

\section{Publisher's Note}

Springer Nature remains neutral with regard to jurisdictional claims in published maps and institutional affiliations.

Received: 10 January 2017 Accepted: 29 March 2017

Published online: 05 April 2017 


\section{References}

1. Kawecki TJ. Adaptation to marginal habitats. Ann Rev Ecol Evol Syst. 2008:39:321-42.

2. Reusch TBH. Climate change in the oceans: evolutionary versus phenotypically plastic responses of marine animals and plants. Evol Appl. 2014;7:104-22.

3. West-Eberhard MA. Developmental plasticity and the origin of species differences. Proc Natl Acad Sci USA. 2005;102:6543-9.

4. Pigliucci M. Phenotypic plasticity: beyond nature and nurture. Baltimore: Johns Hopkins Univ. Press; 2001.

5. Lescak EA, Bassham SL, Catchen J, Gelmond O, Sherbick ML, von Hippe FA, Cresko WA. Evolution of stickleback in 50 years on earthquake-uplifted islands. Proc Natl Acad Sci USA. 2015;112:E7204-12.

6. Hoffmann AA, Sgrò CM. Climate change and evolutionary adaptation. Nature. 2011:470:479-85.

7. Chevin LM, Lande R, Mace GM. Adaptation, plasticity, and extinction in a changing environment: towards a predictive theory. PLOS Biol. 2010:8:e1000357.

8. Keller SR, Taylor DR. Genomic admixture increases fitness during a biological invasion. J Evol Biol. 2010;23:1720-31.

9. Zillén L, Conley DJ, Andren T, Andren E, Björck S. Past occurrences of hypoxia in the Baltic Sea and the role of climate variability, environmental change and human impact. Earth Sci Rev. 2008;91:77-92.

10. Ojaveer H, Jaanus A, MacKenzie BR, Martin G, Olenin S, Radziejewska T, Telesh I, Zettler ML, Zaiko A. Status of biodiversity in the Baltic Sea. PLoS ONE. 2010;5:e12467.

11. Johannesson $\mathrm{K}$, André C. Life on the margin: genetic isolation and diversity loss in a peripheral marine ecosystem, the Baltic Sea. Mol Ecol. 2006:15:2013-29.

12. Luttikhuizen PC, Drent J, Peijnenburg KTCA, Van der Veer HW, Johannes son K. Genetic architecture in a marine hybrid zone: comparing outlier detection and genomic clines analysis in the bivalve Macoma balthica. Mol Ecol. 2012;21:3048-61.

13. Lamichhaney S, Barrio AM, Rafati N, Sundström G, Rubin C-J, Gilbert ER, Berglund J, Wetterbom A, Laikre L, Webster MT, Grabherr M, Ryman N, Andersson L. Population-scale sequencing reveals genetic differentiation due to local adaptation in Atlantic herring. Proc Natl Acad Sci USA. 2012:109:19345-50

14. Bäck S, Ruuskanen A. Distribution and maximum growth depth of Fucus vesiculosus along the Gulf of Finland. Mar Biol. 2000;136:303-7.

15. Forslund $\mathrm{H}$, Eriksson $\mathrm{O}$, Kautsky L. Grazing and geographic range of the Baltic seaweed Fucus radicans (Phaeophyceae). Mar Biol Res. 2012:8:322-30.

16. Tatarenkov A, Bergström $L$, Jonsson RB, Serrão EA, Kautsky L, Johannesson K. Intriguing asexual life in marginal populations of the brown seaweed Fucus vesiculosus. Mol Ecol. 2005:14:647-51.

17. Serrão EA, Kautsky L, Brawley SH. Distributional success of the marine seaweed Fucus vesiculosus L. in the brackish Baltic Sea correlates with osmotic capabilities of Baltic gametes. Oecologia. 1996:107:1-12.

18. Ardehed A, Johansson D, Sundqvist L, Schagerström E, Zagrodzka Z, Kovaltchouk NA, Bergström L, Kautsky L, Rafajlovic M, Pereyra RT, Johannesson K. Divergence within and among seaweed siblings (Fucus vesiculosus and F. radicans) in the Baltic Sea. PLoS ONE. 2016:11:e0161266.
19. Bergström L, Tatarenkov A, Johannesson K, Jonsson RB, Kautsky L. Genetic and morphological identification of Fucus radicans sp Nov (Fucales, Phaeophyceae) in the brackish Baltic Sea. J Phycol. 2005;41:1025-38.

20. Pereyra RT, Bergström L, Kautsky L, Johannesson K. Rapid speciation in a newly opened postglacial marine environment, the Baltic Sea. BMC Evol Biol. 2009;9:70.

21. Pereyra RT, Huenchuñir C, Johansson D, Forslund H, Kautsky L, Jonsson $P R$, Johannesson K. Parallel speciation or long-distance dispersal? Lessons from seaweeds (Fucus) in the Baltic Sea. J Evol Biol. 2013:26:1727-37.

22. Van Alstyne KL. Adventitious branching as a herbivore-induced defense in the intertidal brown alga Fucus distichus. Mar Ecol Prog Ser. 1989;56:169-76.

23. Kawecki TJ, Ebert D. Conceptual issues in local adaptation. Ecol Lett. 2004:7:1225-41.

24. Johannesson $\mathrm{K}$, Johansson D, Larsson KH, Huenchuñir CJ, Perus J, Forslund $\mathrm{H}$, Kautsky L, Pereyra RT. Frequent clonality in fucoids (Fucus radicans and Fucus vesiculosus; Fucales, Phaeophyceae) in the Baltic Sea. J Phycol. 2011:47:990-8.

25. Pritchard JK, Stephens M, Donnelly P. Inference of population structure using multilocus genotype data. Genetics. 2000;155:945-59.

26. Arnaud-Haond S, Belkhir K. GENCLONE: a computer program to analyse genotypic data, test for clonality and describe spatial clonal organization. Mol Ecol Notes. 2007:7:15-7.

27. Tatarenkov A, Jonsson RB, Kautsky L, Johannesson K. Genetic structure in populations of Fucus vesiculosus (Phaeophyceae) over spatial scales from $10 \mathrm{~m}$ to $800 \mathrm{~km}$. J Phycol. 2007;43:675-85.

28. R Core Team. R: A language and environment for statistical computing. R Foundation for Statistical Computing, Vienna, Austria. 2012. ISBN 3-900051-07-0, URL http://www.R-project.org/.

29. Bäck S, Collins JC, Russell G. Effects of salinity on growth of Baltic and Atlantic Fucus vesiculosus. Br Phycol J. 1992:27:39-47.

30. Pearson G, Kautsky L, Serrão E. Recent evolution in Baltic Fucus vesiculosus: reduced tolerance to emersion stresses compared to intertidal (North Sea) populations. Mar Ecol Prog Ser. 2000;202:67-79.

31. Johannesson K, Forslund $H$, Capetillo NÅ, Kautsky L, Johansson D, Pereyra RT, Råberg S. Phenotypic variation in sexually and asexually recruited individuals of the Baltic Sea endemic macroalga Fucus radicans: in the field and after growth in a common-garden. BMC Ecol. 2012;12:2.

32. Ardehed A, Johansson D, Schagerström E, Kautsky L, Johannesson $\mathrm{K}$, Pereyra RT. Complex spatial clonal structure in the macroalgae Fucus radicans with both sexual and asexual recruitment. Ecol Evol. 2015;2015(5):4233-45.

33. Serrão EA, Brawley SH, Hedman J, Kautsky L, Samuelsson G. Reproductive success of Fucus vesiculosus (Phaeophyceae) in the Baltic Sea. J Phycol. 1999;35:254-69.

34. Forslund H, Kautsky L. Reproduction and reproductive isolation in Fucus radicans (Phaeophyceae). Mar Biol Res. 2013;9:262-7.

35. Rafajlović M, Kleinhans D, Gulliksson C, Fries J, Johansson D, Ardehed A Sundqvist L, Pereyra RT, Mehlig B, Jonsson PR, Johannesson K. Neutra mechanisms forming large clones during colonisation of new areas. $J$ Evol Biol. 2017. (awaiting final decision)

\section{Submit your next manuscript to BioMed Central and we will help you at every step:}

- We accept pre-submission inquiries

- Our selector tool helps you to find the most relevant journal

- We provide round the clock customer support

- Convenient online submission

- Thorough peer review

- Inclusion in PubMed and all major indexing services

- Maximum visibility for your research

Submit your manuscript at www.biomedcentral com/submit
C BioMed Central 